In today's marketplace, price bundling is widespread: Manufacturers and retailers routinely offer multiple products for a single, bundled price. Although the effects of price bundling on purchase behavior have been well researched, the effects of price bundling on postpurchase consumption behavior have received almost no attention. In this article, the authors build on the sunk cost literature (e.g., Thaler 1980, 1985) and predict that price bundling leads to a disassociation or "decoupling" of transaction costs and benefits, thereby reducing attention to sunk costs and decreasing a consumer's likelihood of consuming a paid-for service (e.g., a theater performance). Four studies show this to be the case. In two lab studies, the authors show that having a bundled four-day ski pass as opposed to four one-day ski tickets decreases a person's likelihood of skiing on the final day of a four-day ski vacation. They replicate this result in a field study, showing that multiperformance ticket holders are more likely to forgo a given theatrical performance than are single-performance ticket holders, all else held constant. In a final study, the authors show that the decreased attention to sunk costs brought about by price bundling can be either cognitively driven (i.e., it is difficult to allocate a single payment across multiple benefits) or motivationally driven (i.e., there is an underlying desire to avoid consumption). Their findings have practical implications for managers interested in predicting or influencing actual product consumption.

\title{
Transaction Decoupling: How Price Bundling Affects the Decision to Consume
}

In today's marketplace, the practice of price bundling is widespread. Manufacturers and retailers routinely offer single units of multiple products or multiple units of the same product for one bundled price. Theater companies and sports teams offer season tickets; Club Med provides vacation packages that include airfare, hotel, and meals; McDonald's offers "value meals" that include a sandwich, a soft drink, and french fries; and liquor stores sell wines by the case.

Not surprisingly, the effects of price bundling on purchase behavior have been well researched. The economics literature provides prescriptions for when and why price bundling is a revenue-maximizing or profit-maximizing

*Dilip Soman is Assistant Professor of Marketing, Hong Kong University of Science and Technology (e-mail: mksoman@ust.hk). John T. Gourville is Associate Professor of Marketing, Graduate School of Business Administration, Harvard University (e-mail: jgourville@hbs.edu). Both authors contributed equally to the research reported in this article. The authors thank Chris Hsee, Luc Wathieu, and the four anonymous JMR reviewers for their comments on previous drafts of this article. They also thank Julien Cayla, Kareen Kinzli, and Michael Walker for their assistance in data collection. The studies reported in this article were conducted while Soman was at the College of Business, University of Colorado at Boulder, and that university's support is acknowledged. strategy (see Dolan and Simon 1996; Guiltinan 1987; Hanson and Martin 1990). In the consumer behavior literature, researchers have explored the processes people employ to value overall bundles and items within bundles (see Drumwright 1992; Gaeth et al. 1990; Harlam et al. 1995; Yadav and Monroe 1993). These works suggest that price bundling often can and should decrease price sensitivity and increase purchase likelihood.

In comparison, almost no research has examined the effect of price bundling on consumption behavior. In particular, aside from speculation by Prelec and Loewenstein (1998), little is understood about how price bundling affects the likelihood of consuming a purchased product. Considering the significant effects product consumption can have on everything from service use to product repurchase, this lack of research is surprising. For example, a theater manager wishing to maximize revenues (e.g., by selling stand-by tickets) or minimize costs (e.g., by optimally staffing the theater) should be interested in how the selling of season tickets affects the likelihood of attendance. Similarly, a packaged goods manufacturer wishing to increase sales should be interested in how bundling affects the rate of product consumption. 
With these issues in mind, this article investigates how and why price bundling affects the consumption of a servicebased product, such as a sporting event or a theater performance. ${ }^{1}$ As an illustration, consider the following scenario:

Ernie and Bert are serious skiers who have each prepurchased four days' worth of lift tickets. Having gone to different vendors, Emie paid $\$ 40$ for each of four oneday lift tickets, and Bert paid $\$ 160$ for a four-day ski pass. Both men have enjoyed three days of skiing in perfect conditions. Unfortunately, each wakes up on the fourth day to find that ski conditions have deteriorated considerably. Who is more likely to ski in spite of the poor conditions-Ernie, who has a nonrefundable, unused ticket for that fourth day, or Bert, who has a partially used pass that expires on that fourth day?

From an economic perspective, the format of Ernie's or Bert's ticket should have no impact on either man's decision to ski. Each man should view the money spent on his lift ticket as nonrecoverable or "sunk" and base his decision solely on the incremental costs and benefits of skiing in poor conditions. In this regard, both men face identical costs and benefits and should be equally likely (or unlikely) to ski.

However, existing research on decision making suggests that each man will consider the sunk cost of his lift ticket, increasing his likelihood of skiing on that final day (Arkes and Blumer 1985; Thaler 1980). But, having each paid an identical amount, the men face the same sunk cost and, again, should be equally likely to ski on day four.

Contrary to both these perspectives, we argue that Ernie and Bert will differ in their likelihood of skiing on the fourth day and that this difference will be driven by the format of their lift tickets. We believe that Ernie, who has paid $\$ 40$ for each of four one-day lift tickets, will perceive little ambiguity as to the cost of skiing on any given day. This lack of ambiguity should result in a tight "coupling" between the cost and the benefit of skiing on the fourth day, leading to a strong attention to sunk costs and a relatively high likelihood of skiing in spite of the poor conditions.

In contrast, we believe that Bert, who has paid $\$ 160$ for a four-day ski pass, will perceive far greater ambiguity as to the cost of skiing on any given day. This ambiguity should result in a disassociation or "decoupling" of the cost and the benefit of skiing on the fourth day (Gourville and Soman 1995; Prelec and Loewenstein 1998), leading to a weaker attention to sunk costs and a relatively low likelihood of skiing in the poor conditions.

More broadly, we argue that the well-known sunk cost effect is moderated by the ambiguity inherent in a bundled transaction. For unbundled transactions, costs and benefits are unambiguously linked with each other, resulting in a strong sunk cost effect. But for bundled transactions, the link between costs and benefits is open to interpretation and could result in a much weaker sunk cost effect. For a service-based offering that is due to expire (e.g., a sporting

In a recent article, Gourville and Soman (1998) investigate the effects of advanced payment on product consumption. They find that as the delay between payment and consumption increases, the sunk cost impact of the payment decreases. This decreases subjects' likelihood of consuming a paid-for service (e.g., a sporting event) but increases their likelihood of frivolously consuming a paid-for physical good (e.g., a bottle of wine). In this article, we focus our investigation on service-based products. event), this weaker sunk cost effect should decrease the likelihood of consumption.

The rest of this article is organized into four sections. First, we review literature relevant to the sunk cost effect. Second, we propose our theory of transaction decoupling. Third, we present three laboratory studies and one field study that explore the existence and causes of transaction decoupling. Fourth, we conclude with a general discussion and directions for further research.

\section{MENTAL ACCOUNTING AND THE SUNK COST EFFECT}

It is well documented that consumers consider historic, nonrecoverable transaction costs when deciding on a future course of action (Arkes and Blumer 1985; Garland and Newport 1991; Simonson and Staw 1992; Staw 1976; Thaler 1980). In one well-known scenario, Thaler (1980) notes that a family is more likely to brave a snowstorm and drive to a basketball game when they have paid $\$ 40$ for tickets to that game than when they have received those same tickets for free. Similarly, Arkes and Blumer (1985) show that when people are presented with a scenario in which they have mistakenly purchased both a $\$ 50$ ski vacation and a $\$ 100$ ski vacation for the same weekend, $54 \%$ of them choose the $\$ 100$ vacation over the $\$ 50$ vacation in spite of anticipating greater enjoyment from the $\$ 50$ vacation.

This behavior has been termed the sunk cost effect and has been defined as the "greater tendency to continue an endeavor once an investment in money, time, or effort has been made" (Arkes and Blumer 1985, p. 124). According to economic theory, such behavior is irrational. When deciding whether to continue an endeavor, historic and nonrecoverable costs incurred in pursuit of that endeavor should be ignored, and only future costs and benefits should be considered. In Thaler's basketball game scenario, for example, whether tickets are free or paid for should be irrelevant to a family's decision to attend the game. Rather, the decision should rest solely on the incremental costs (e.g., gas, time, anxiety of driving) and benefits (e.g., enjoyment) of going. Twenty years of research suggests that this basic tenet of rational economics is routinely violated.

\section{Explaining the Sunk Cost Effect}

There are a host of potential explanations for the sunk cost effect. These include people's tendency to be risk seeking in light of prior losses (Garland and Newport 1991; Kahneman and Tversky 1979; Thaler 1980; Whyte 1986), people's desire not to appear wasteful (Arkes 1996), and people's desire to justify a prior course of action to themselves or others (Brockner 1992; Staw 1976; Teger 1980). Although each of these explanations taps into fundamentally different cognitive processes (e.g., being risk-seeking versus preserving self-image), they share an important characteristic for the purposes of the current research. Each explanation requires that a person be sensitive to, or track, the costs incurred during a particular course of action.

In the case of a consumer transaction, Thaler (1980, 1985) proposes one mechanism by which such tracking might take place. He argues that a consumer creates a "mental account" upon entering a transaction (e.g., making payment) and closes that account upon completing the transaction (e.g., consuming the good or service). By establishing a transaction-specific mental account, the consumer creates a psychological link between the costs and the benefits of a 
given transaction. Prelec and Loewenstein (1998) refer to this psychological linking of transaction costs and benefits as coupling.

According to Thaler's $(1980,1985)$ mental accounting framework, no loss or pain is experienced at the time a person pays for a product. Rather, the payment is held in the appropriate mental account until the transaction is completed. If the product is consumed as planned, the consumer closes the mental account by canceling the costs of the transaction against the benefits received. If the consumer forgoes the pending benefit, however, he or she will be forced to close the account without an offsetting benefit and will be compelled to recognize the cost of the transaction as a painful loss. Therefore, all else being equal, the family in Thaler's basketball scenario experiences greater pressure to attend the game when the tickets are paid for (to avoid a perceived loss of $\$ 40$ ) than when the tickets are free (and there is no loss to avoid). ${ }^{2}$

\section{PRICE BUNDLING AND TRANSACTION DECOUPLING}

Implicit in Thaler's (1980, 1985) and others' explanations for the sunk cost effect is the assumption that a person uniquely identifies and subsequently considers the costs of an endeavor when deciding whether to continue that endeavor. For consumer transactions, this would require the unambiguous identification and consideration of the costs of a particular purchase decision.

However, recent research suggests that the identification and consideration of such costs may not be straightforward. Gourville and Soman (1998) show that when the costs of a transaction significantly precede the benefits (e.g., advancepurchased concert tickets), the purchaser gradually adapts to the upstream costs to the point at which those costs have little sunk cost impact on the consumption of the pending benefit. And Prelec and Loewenstein (1998) speculate that it is significantly more difficult to identify and consider the (sunk) cost of a purchased product when that cost is incurred by credit card than by cash. These articles suggest that the physical characteristics of a transaction can significantly affect attention to the (sunk) costs of that transaction and, in turn, a person's likelihood of consuming the purchased product.

\section{The Effect of Price Bundling}

Our present research considers the impact of price bundling on a consumer's accounting of the (sunk) costs of a given transaction. We propose that it is relatively easy to identify and account for costs in a simple cash-and-carry type of transaction-that is, a transaction in which a single payment results in a single unit of consumption, as when a person pays 75 for a can of soda. We also believe that it is harder to identify and account for costs in a price-bundled transaction-that is, a transaction in which a single price pays for multiple units of consumption, as when a person pays $\$ 5$ for a sandwich, french fries, and a soda.

Specifically, we argue that in an unbundled transaction (e.g., the purchase of a ticket to a play), the relationship

\footnotetext{
${ }^{2}$ Arkes and Blumer (1985) extend this reasoning to argue that the psychological impact of any past payment on future consumption increases monotonically with the size of that payment. As a result, if this family is more likely to go to the game having spent $\$ 40$ as opposed to $\$ 0$, the family also should be more likely to go having spent $\$ 40$ as opposed to $\$ 20$.
}

between the costs and the benefits of that transaction is oneto-one: A single payment provides a single unit of consumption. As such, there is little ambiguity as to what costs are paying for what benefits, which results in a strong association, or coupling, of those costs and benefits. This coupling, in turn, leads to a heightened attention to the sunk costs of the transaction and a decreased willingness to forgo the consumption of the pending benefit. We argue that this is the case in Thaler's basketball game/snowstorm scenario.

In contrast, in a bundled transaction (e.g., the purchase of season tickets to a play series), the relationship between the costs and the benefits of that transaction is one-to-many: A single payment provides multiple units of consumption. In such a transaction, there is far greater ambiguity as to what costs are paying for what benefits. As a result, price bundling may lead to the psychological disassociation, or decoupling, of transaction costs and benefits such that the costs become less relevant to the consumption decision. As a direct consequence, there is a decreased attention to sunk costs and an increased willingness to forgo any individual benefit within the bundle. We capture this thinking in the following hypothesis:

\section{$\mathrm{H}_{1}$ : Relative to an unbundled transaction, a bundled transaction will result in a greater willingness to forgo any individual unit of consumption.}

We now describe four studies designed to test this hypothesis.

\section{STUDY I}

In Study 1, we presented subjects with a ski vacation scenario similar to that faced by Ernie and Bert. We asked subjects to imagine that they had prepurchased lodging and lift tickets for a four-day ski vacation. We framed the cost of the entire vacation and the cost of lift tickets within that vacation as either a bundled transaction or an unbundled transaction. All subjects were then presented with a final day of skiing in poor weather conditions. In keeping with $\mathrm{H}_{1}$, we expected the bundling of the vacation and/or the lift tickets to increase transaction decoupling, thereby decreasing subsequent sunk cost behavior. As a result, we expected subjects facing bundled transactions to be less likely to ski on the final day than subjects facing unbundled transactions.

\section{Method}

Subjects. Subjects were 80 undergraduates from the University of Colorado who were approached on campus and were asked to fill out a one-page questionnaire. They were not paid.

Design and procedure. In the questionnaire, we asked subjects to imagine that they were on a four-day Colorado ski vacation, for which they had prepurchased four nights of lodging and four days of lift tickets. Across all subjects, the combined cost of the lodging and lift tickets was $\$ 560$. However, we manipulated the manner in which this $\$ 560$ expense was presented in a 2 (Lift Tickets) $\times 2$ (Vacation) between-subjects, full-factorial design.

For the first factor, Lift Tickets, we told half the subjects that they had prepurchased a single four-day ski pass for $\$ 160$ (Bundled Pass). These subjects were shown a representative pass to emphasize the format. We told the other half of the subjects that they had prepurchased four one-day ski tickets for $\$ 40$ each (Unbundled Tickets). These subjects were shown four one-day tickets, also to emphasize the for- 
mat. We told all subjects that their tickets/passes were nonrefundable and could not be resold.

For the second factor, Vacation, we told half the subjects that they had prepurchased a vacation package for $\$ 560$, consisting of a mountainside condominium costing $\$ 400$ and the previously described ski pass or tickets (Bundled Vacation). We told the other half of the subjects that they had rented a mountainside condominium costing $\$ 400$ and had separately purchased the described ski pass or tickets (Unbundled Vacation). ${ }^{3}$

Following their respective expense scenario, we presented each subject with the following:

\begin{abstract}
It is now the morning of the last day of your vacation. You have had three excellent days of skiing with perfect conditions. Unfortunately, last night a warm rain hit the area. While skiing is still permitted, it may not be much fun. As an alternative, a friend suggests taking it easy, having a nice lunch, and leaving early to beat the traffic. You look at your [ski pass/remaining ski ticket] and are not sure if you want to go sking or leave early.
\end{abstract}

Finally, we asked subjects to indicate how likely they would be to ski on that final day and provided them with a tenpoint response scale on which to respond $(1=$ "definitely will not go skiing," $10=$ "definitely will go skiing").

\section{Results and Discussion}

All subjects had incurred lodging and lift ticket expenses totaling $\$ 560$. Subjects differed only in whether those expenses were bundled or unbundled. Rationally, such differences should have been irrelevant to their decisions to ski on the fourth day. According to transaction decoupling, however, both the lift ticket bundling and the vacation bundling should have significantly decreased a subject's likelihood of skiing on that final day.

To test this, subjects' likelihood responses were analyzed in a 2 (Lift Tickets) $\times 2$ (Vacation) analysis of variance (ANOVA). This analysis revealed a significant main effect for Lift Tickets; subjects were significantly less likely to ski if they held a bundled pass than if they held an unbundled, one-day ski ticket $\left(\mathrm{X}_{\mathrm{Bundled}}\right.$ Pass $=3.63$ versus $\mathrm{X}_{\text {Unbundled }}$ Tickets $=5.17 ; \mathrm{F}_{1,76}=10.17, p<.005$ ). It also revealed a significant main effect for Vacation; subjects were significantly less likely to ski if their entire vacation was bundled $\left(\mathrm{X}_{\mathrm{Bundled}}\right.$ Vacation $=3.90$ versus $\mathrm{X}_{\text {Unbundled vacation }}=4.90$; $\left.F_{1,76}=4.23, p<.05\right)$. The Lift Ticket $\times$ Vacation two-way interaction did not prove significant $\left(\mathrm{F}_{1.76}=1.28, p>.25\right)$.

On the basis of these results, it appears that consumption behavior is influenced by price bundling in a manner consistent with transaction decoupling. Specifically, subjects were significantly less likely to ski on the final day after having incurred a bundled expense. However, there exists an alternative explanation for these results. According to Thaler's $(1980,1985)$ theory of mental accounting, the psychological impact of any one payment within a bundle of payments decreases because of the psychophysics of aggre-

\footnotetext{
3Thus, subjects found themselves in one of four scenarios: Expenses were presented as (1) a $\$ 560$ bundled vacation that included a bundled ski pass worth $\$ 160$, (2) a $\$ 560$ bundled vacation that included four unbundled ski tickets worth $\$ 40$ each, (3) an unbundled vacation that included $\$ 400$ in lodging and a bundled ski pass worth $\$ 160$, or (4) an unbundled vacation that included $\$ 400$ in lodging and four unbundled ski tickets worth $\$ 40$ each.
}

gation of costs. Given a convex utility function in the domain of losses (Kahneman and Tversky 1979), $\$ 40$ for a fourth day of skiing may seem less painful when bundled with the $\$ 120$ for the other three days because of the diminishing marginal impact of increasingly higher costs. Specifically, $\$ 40$ as part of a $\$ 160$ expense-that is, $V(-\$ 160)-V(-\$ 120)$-is on the flatter portion of the loss function and has a smaller psychological impact than $\$ 40$ evaluated separately-that is, V(-\$40). Therefore, the results in Study 1 could be due to either transaction decoupling or the psychophysics of aggregated costs. Study 2 was designed to test these two explanations.

\section{STUDY 2}

In Study 2, we again employed a ski scenario involving bundled passes and unbundled tickets. In addition, however, we included a third, Semibundled Tickets condition in which the monetary format of the tickets was bundled (i.e., cost was quoted as a single price) but the physical format of the tickets was unbundled (i.e., a separate ticket for each day). Figure 1 highlights the experimental design of this second study.

If the effects observed in Study 1 are due purely to the psychophysics of aggregated costs, we would expect subjects to be less likely to ski when the ticket costs are monetarily bundled - that is, in the Bundled Pass and the Semibundled Tickets conditions. If the effects are due to transaction decoupling, however, we would expect subjects to be less likely to ski when the tickets are physically bundled-that is, in the Bundled Pass condition only. Thus, as reflected in Figure 1, the Semibundled Tickets offer a "swing" condition that should help distinguish between the two potential explanations for the results observed in Study 1 .

Study 2 also included several additional dependent measures that were expected to correlate with subjects' attention to sunk costs. These include the pain and regret experienced upon missing the final day of skiing, a person's likelihood of prepurchasing the same type of lift ticket in the future, and the refund that would be considered fair compensation for the missed final day. These added measures were included to provide a richer understanding of the implications of price bundling.

\section{Method}

Subjects. Subjects were 150 students at the University of Colorado who were approached on campus and asked to fill out a one-page questionnaire. They were not paid.

Design and procedure. In the questionnaire, we asked subjects to imagine that they had prepurchased four days' worth of lift tickets to a popular Colorado ski resort. The physical bundling and the monetary bundling of these lift tickets were manipulated across subjects, forming three conditions. In the Unbundled Tickets condition, we told subjects that they had prepurchased four one-day ski tickets for $\$ 40$ each. Thus, these tickets were physically unbundled (i.e., four separate tickets) and monetarily unbundled (i.e., $\$ 40$ per ticket). In the Semibundled Tickets condition, we told subjects that they had prepurchased four one-day tickets for $\$ 160$. Thus, these tickets were physically unbundled but monetarily bundled (i.e., $\$ 160$ for four tickets). And in the Bundled Pass condition, we told subjects that they had purchased a single ski pass good for all four days for $\$ 160$. Thus, these tickets were both physically and monetarily 
bundled. An illustration showing the corresponding ticket format accompanied each survey (see Figure 2).

Subjects were next told, "It is now the morning of the last day of your vacation. You have had three excellent days of skiing with perfect conditions. Unfortunately, last night a warm rain hit the area. While skiing is still permitted, it may not be much fun. As an alternative, a friend suggests taking it easy, having a nice lunch, and leaving early to beat the traffic."

Finally, we asked subjects five questions designed to assess their attention to the (sunk) cost of the final day of skiing. We asked them (1) how likely they were to ski on the final day (SKI), (2) how painful it would be to forgo skiing on the final day (PAIN), (3) how much regret they would feel if they did not use the remaining portion of their lift tickets (REGRET), (4) how likely they would be to repurchase the same type of lift tickets in the future (REPURCHASE), and finally (5) what would be a fair refund for that final day of skiing (REFUND).

For the first four questions, subjects were provided with ten-point response scales, where higher numbers indicated (1) a greater likelihood of skiing, (2) greater pain at forgoing skiing, (3) greater regret at forgoing skiing, and (4) a lower likelihood of purchasing the same ticket type in the future. Question 5 allowed for a free response. Therefore, for each of the five dependent variables, larger values reflected a lower degree of transaction decoupling and a greater attention to sunk costs.

\section{Results and Discussion}

The Bundled Pass and the Unbundled Tickets conditions were functionally identical to those employed in Study 1 . Thus, we expected subjects in the Bundled Pass condition to be significantly less likely to go skiing (SKI) than subjects in the Unbundled Tickets condition. In keeping with a decreased attention to sunk costs, we also expected subjects in the Bundled Pass condition to report less pain and less regret, demand a smaller refund, and be more likely to repurchase similar tickets in the future.

For subjects in the Semibundled Tickets condition, if the attenuation of sunk costs is due to the psychophysics of aggregated costs (Thaler 1985), we would expect them to behave like subjects in the Bundled Pass condition. If the attenuation is due to transaction decoupling, however, we would expect them to behave like subjects in the Unbundled Tickets condition. And if both forces are contributing to the attenuation of sunk costs, we would expect the responses of subjects in the Semibundled Tickets condition to fall between the responses of subjects in the Bundled Pass condition and the responses of subjects in the Unbundled Tickets condition.

Subjects' mean responses on each of the five dependent variables across the three experiment conditions are shown in Table 1. These data were analyzed with one-way ANOVAs for each of the dependent variables, with Ticket Format as the independent variable. Ticket Format had a significant effect on all the dependent variables: SKI $\left(\mathrm{F}_{2,147}=17.53, p<.001\right)$, PAIN $\left(\mathrm{F}_{2,147}=20.82, p<.001\right)$, REGRET $\left(\mathrm{F}_{2,147}=16.49, p<.001\right)$, REFUND $\left(\mathrm{F}_{2,147}=\right.$ $16.62, p<.001)$, and REPURCHASE $\left(\mathrm{F}_{2,147}=9.04, p<\right.$ $.001)$.

More important, as the data in Table 1 suggest, these main effects were due to pairwise differences across all three ticket formats. For example, planned contrasts revealed that the mean likelihood of skiing (SKI) on the final day was significantly greater for Unbundled Tickets subjects than for Semibundled Tickets subjects (6.74 versus $\left.5.40 ; \mathrm{F}_{1,147}=8.02, p<.01\right)$ and significantly greater for Semibundled Tickets subjects than for Bundled Pass subjects $\left(5.40\right.$ versus $\left.3.94 ; \mathrm{F}_{1,147}=9.52, p<.005\right)$. Identical patterns of significant contrasts were obtained for the other four dependent variables.

Figure 1

MANIPULATION OF PHYSICAL AND MONETARY BUNDLING ACROSS TICKET FORMAT CONDITIONS: STUDY 2

\section{Physically Unbundled High Transaction Coupling}

\begin{tabular}{|c|}
\hline Semibundled Tickets \\
\hline 160 for four tickets \\
Physically unbundled \\
Monetarily bundled
\end{tabular}

Physically Bundled High Transaction Decoupling

\begin{tabular}{|c|}
\hline Bundled Pass \\
$\$ 160$ for a four-day pass \\
Physically bundled \\
Monetarily bundled
\end{tabular}

Monetarily Unbundled Low Aggregation of Losses
Monetarily Bundled High Aggregation of Losses 
This pattern of results suggests that both the psychophysics of aggregated costs and transaction decoupling play a significant role in the observed attenuation of the sunk cost effect. The difference in the means between the Unbundled Tickets and Semibundled Tickets conditions is consistent with Thaler's (1985) notion that the incremental pain associated with a cost is smaller when that cost is aggregated with other costs. At the same time, the difference in means between the Semibundled Tickets and the Bundled Pass conditions is consistent with transaction decoupling.

In summary, Study 1 shows that consumers are more willing to forgo consumption when a benefit is obtained through a one-to-many, or bundled, transaction as opposed to a one-to-one, or unbundled, transaction. Study

Figure 2

MANIPULATION OF TICKET FORMAT: STUDY 2
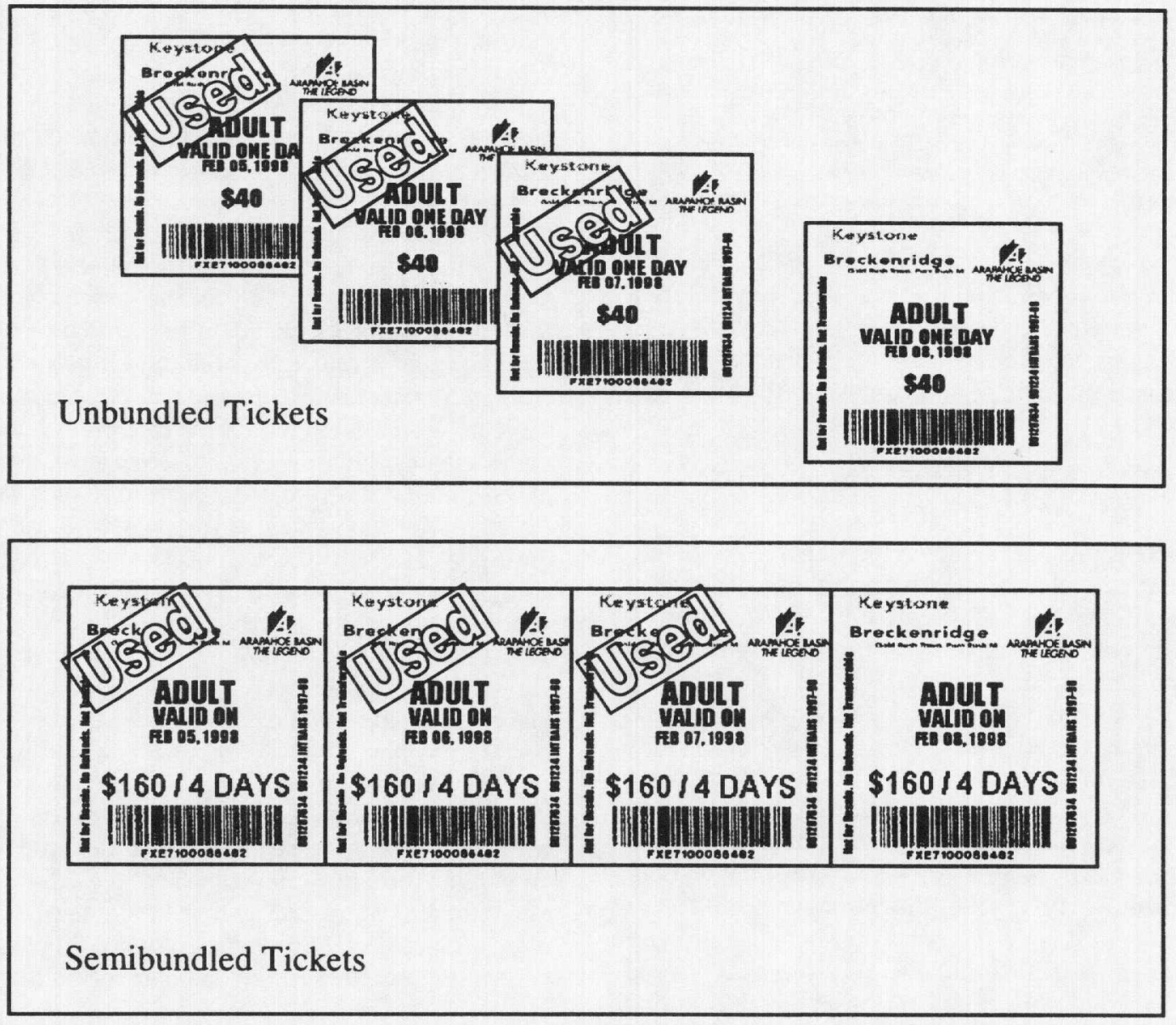

Bundled Pass

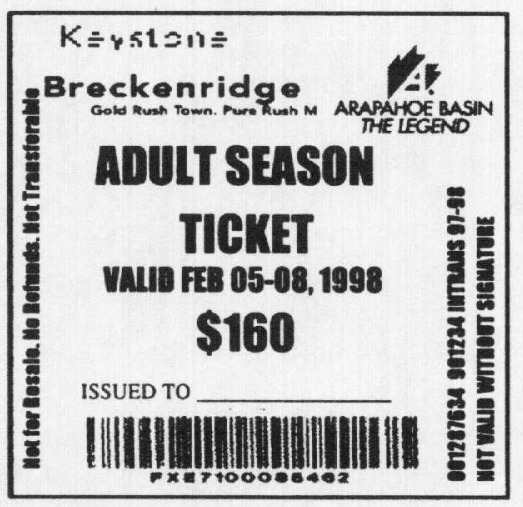


Table 1

EFFECT OF TICKET FORMAT ON DEPENDENT VARIABLES: STUDY 2

\begin{tabular}{|c|c|c|c|}
\hline \multirow[b]{2}{*}{$\begin{array}{l}\text { Dependent } \\
\text { Variable }\end{array}$} & \multicolumn{3}{|c|}{ Ticket Format } \\
\hline & $\begin{array}{l}\text { Unbundled } \\
\text { Tickets } \\
(n=50)^{a}\end{array}$ & $\begin{array}{c}\text { Semibundled } \\
\text { Tickets } \\
(n=50)^{b}\end{array}$ & $\begin{array}{c}\text { Bundled } \\
\text { Pass } \\
(n=50)\end{array}$ \\
\hline SKI & $6.74 * *$ & $5.40^{++}$ & 3.9 \\
\hline PAIN & $6.64^{* * *}$ & $4.94^{+}$ & 3.82 \\
\hline REGRET & $6.48 * *$ & $5.06+$ & 3.92 \\
\hline REPURCHASE & $7.20^{*}$ & $5.26^{+}$ & 4.18 \\
\hline REFUND & $\$ 34.38^{* *}$ & $\$ 28.48^{++}$ & $\$ 22.12$ \\
\hline
\end{tabular}

aAsterisks indicate pairwise planned contrasts between Unbundled Tickets and Semibundled Tickets: ${ }^{*} p<.05,{ }^{* *} p<.01$, and ${ }^{* * *} p<.001$.

bPluses indicate pairwise planned contrasts between Semibundled Tickets and Bundled Passes: ${ }^{+} p<.05,++p<.01$, and ${ }^{+++} p<.001$.

Notes: Higher means indicate higher likelihood of skiing, greater pain, greater regret, and lower likelihood of ticket repurchase.

2 replicates and extends this finding and suggests that though the results can be partially explained by the psychophysics of aggregated costs (Thaler 1985), transaction decoupling also significantly contributes to the observed effects.

\section{PSYCHOLOGICAL CAUSES OF TRANSACTION DECOUPLING}

Studies 1 and 2 provide evidence of transaction decoupling and help distinguish its effects from those of the psychophysics of aggregated costs. However, the question of what psychological mechanisms drive transaction decoupling remains unanswered.

Consider the subjects in Studies 1 and 2 who were told that they had purchased a bundled pass. These subjects may have displayed a high degree of transaction decoupling because it was motivationally advantageous to do so. In particular, these subjects may have opportunistically decoupled the costs and benefits of that final day to avoid skiing in poor conditions. If this was the case, however, we would have expected subjects to couple the costs and benefits strongly on that final day to motivate a full day of skiing had the final day offered ideal conditions. Thus, if transaction decoupling is motivationally driven, we would expect decoupling to increase and consumption to decrease as the attractiveness of the consumption opportunity declines.

Alternatively, the Bundled Pass subjects may have displayed a high degree of transaction decoupling because it was cognitively difficult to allocate the cost of the pass over the four days of skiing. In short, subjects may have ignored the cost of the final day of skiing because it was difficult to figure out what that cost was. Thus, if decoupling is cognitively driven, we would expect decoupling to increase and consumption to decreases, as it becomes increasingly difficult to allocate the cost of a bundled purchase across individual elements within that purchase.

These two potential explanations are captured in the following hypotheses:

$\mathrm{H}_{2}$ : Transaction decoupling will increase as the relative attractiveness of the consumption opportunity decreases (i.e., the motivation hypothesis)
$\mathrm{H}_{3}$ : Transaction decoupling will increase as the inherent difficulty in allocating costs across the individual benefits of a transaction increases (i.e., the difficulty hypothesis).

Study 3 was designed to test these two hypotheses and determine if either, or both, help explain transaction decoupling.

\section{STUDY 3}

Manufacturers and retailers often practice a form of price bundling in which they offer one free unit of a product with the full-priced purchase of additional units of the same product. For example, retailers might offer a "buy-two-get-onefree," or BTGO, promotion, in which one free unit of a product is offered with the purchase of two full-priced units of the same product. Study 3 employed such a BTGO promotion to test our hypotheses.

In Study 3, we asked subjects to imagine that they had decided to spend $\$ X$ per ticket for one ticket to each of three theatrical plays, where $\$ X$ varied across subjects. We then told subjects that because of a special BTGO promotion, they would receive a ticket to one of these three plays for free. Thus, instead of having to spend the expected $\$ 3 \mathrm{X}$, they only had to spend $\$ 2 X$ for the three tickets. In addition, for half the subjects, we identified which of the three plays was the free play, thereby providing little flexibility in allocating costs across the three plays. For the other half of the subjects, we did not identify the free play, thereby providing much greater flexibility in allocating costs across the three plays. Finally, we told all subjects that after having enjoyed the first two plays, they were faced with a conflict for the third play. For half of the subjects, this conflict was a desirable party. For the other half of the subjects, it was an undesirable request to help a friend move to a new apartment.

If transaction decoupling is motivationally driven $\left(\mathrm{H}_{2}\right)$, we would expect the subjects who had flexibility in allocating costs to opportunistically couple the costs and benefits of the third play on the basis of the desirability of the conflict they faced - either the party or the move. In contrast, if transaction decoupling is driven by cognitive difficulty $\left(\mathrm{H}_{3}\right)$, we would expect these subjects to couple the costs and benefits of the third play on the basis of the difficulty they experience in allocating $\$ 2 \mathrm{X}$ across the three plays. And if both motivation and cognitive difficulty contribute to transaction decoupling, we should find support for both hypotheses.

\section{Method}

Subjects. Subjects were 480 University of Colorado undergraduates who were approached on campus and asked to fill out a one-page questionnaire. They were not paid.

Design and procedure. In the questionnaire, we asked subjects to imagine that they had decided to see three plays on successive weekends at a local theater. We told them that they had expected to pay the full price for one ticket to each of these three plays but had encountered a BTGO promotion just before making payment. As a result, the final price paid was only two-thirds of the expected price. We also told them that they had enjoyed the first two plays and that the third play was now just one day away. Finally, we presented subjects with a conflicting event and asked them whether they would attend the play or the conflicting event. Within this basic scenario, we manipulated three factors in a 2 (Conflict) $\times 3$ (Frame) $\times 2$ (Difficulty) between-subjects, full-factorial design. 
The first factor, Conflict, varied the attractiveness of the conflicting event that subjects faced. We told subjects in the Party condition that a friend had invited them to a party to be held the same night as the third play. In contrast, we told subjects in the Move condition that a friend had asked for help moving into a new apartment on the same night as the third play. A priori, we expected subjects to view the party as more desirable than the play and to view the move as less desirable than the play. This was confirmed in a pretest. Twenty pretest subjects rated the party as more attractive than the play and the move as less attractive than the play, for a significant overall difference $\left(\mathrm{X}_{\text {Party }}=+2.9, \mathrm{X}_{\text {Move }}=\right.$ $-1.3, p<.05) .^{4}$

The second factor, Frame, varied how the BTGO promotion was framed. We told subjects in the Paid-For condition that the first play was free and the second and third plays were full priced. We told subjects in the Free condition that the first and second plays were full priced and the third play was free. Finally, we told subjects in the Ambiguous condition that one of the three plays was free, but we did not specify which one.

We included this second factor to test the motivation hypothesis $\left(\mathrm{H}_{2}\right)$. We expected subjects in the Paid-For conditions to view the third play as full priced regardless of the type of conflict they faced, which would result in a strong sunk cost effect. Similarly, we expected subjects in the Free conditions to view the third play as free regardless of the type of conflict they faced, which would result in a weak sunk cost effect. In contrast, we expected the Ambiguous framing to offer subjects the flexibility to allocate costs according to their underlying desires. In particular, under the motivation hypothesis, we expected subjects in the Ambiguous conditions to view the third play as free when facing the desirable party, which would negatively affect play attendance, but to view the third play as full priced when facing the undesirable move, which would positively affect play attendance.

The third factor, Difficulty, varied the final price paid for the three plays- $\$ 30, \$ 37.86, \$ 52.58$, or $\$ 60$. Some subjects in the Low Difficulty condition were told that the final price was $\$ 30$, others were told that it was $\$ 60$. Similarly subjects in the High Difficulty condition were told that the final price was either $\$ 37.86$ or $\$ 52.58 .5$ To justify these final prices, we told subjects that the full price for a single ticket to any one play, after tax and handling fees, was $\$ 15, \$ 18.93$, $\$ 26.29$, or $\$ 30$. We then told subjects that because of the

\footnotetext{
${ }^{4}$ Subjects were asked to make two ratings. First, they were asked to rate the attractiveness of the party relative to the play. Second, they were asked to rate the attractiveness of the move relative to the play. For each question, subjects were provided an 11 -point scale ranging from -5 ("extremely unattractive relative to the play") to +5 ("extremely attractive relative to the play"), where 0 represented indifference ("equally attractive as the play").

5 Existing research on the information processing of numerical information (see Estelami 1999) suggests that rounded values, such as $\$ 30$ and $\$ 60$, would be easy to allocate across the three plays but that irregular price endings, such as $\$ 37.86$ and $\$ 52.58$, would be difficult to allocate. These expectations were confirmed in a computer-based pretest in which 25 subjects were asked to choose the correct per-unit cost from annong four potential answers for each of the four BTGO promotions used in this study. Reaction time data indicate that subjects found it significantly more difficult to choose the correct per-unit cost for $\$ 37.86$ and $\$ 52.58$ than for $\$ 30$ and $\$ 60\left(X_{\$ 37.86}=14.99\right.$ seconds, $X_{\$ 52.58}=20.31$ seconds versus $\mathrm{X}_{\$ 3,1}=4.59$ seconds, $\mathrm{X}_{\$(1)}=4.25$ seconds; $p<.001$ ), suggesting that our manipulation of Difficulty was effective
}

BTGO promotion, the final price paid for the three tickets was $\$ 30, \$ 37.86, \$ 52.58$, or $\$ 60.6$

We included this third factor to test the difficulty hypothesis $\left(\mathrm{H}_{3}\right)$. We expected subjects to have little difficulty allocating either $\$ 30$ or $\$ 60$ across the three plays. As such, under the difficulty hypothesis, we expected these subjects to allocate costs fully across the three plays and to behave as if the third play cost $\$ 10$ or $\$ 20$, respectively. In contrast, we expected subjects to have difficulty allocating $\$ 37.86$ and $\$ 52.58$ across the three plays. As a result, we expect these subjects to forgo allocating costs and behave as if the third play was free, which would thereby negatively affect play attendance.

After reading their respective scenarios, we asked subjects two questions. First, we asked subjects to indicate their relative likelihood of choosing the third play versus choosing the party/move. Subjects responded on a nine-point scale $(1$ = "definitely choose party/move," $9=$ "definitely attend play"). Second, we asked each subject, "If you had the option of reselling the play ticket, what is the minimum price that you would be satisfied with?"

\section{Results}

We used separate 2 (Conflict) $\times 3$ (Frame) $\times 2$ (Difficulty) ANOVAs to analyze subjects' likelihood of attending the third play (ATTEND) and subjects' fair price for ticket resale (FAIRPRICE). For both ANOVAs, the total price paid for the three tickets (i.e., Total Price) was included as a potential covariate to control for an anticipated main effect of total price on play attendance.

The results from the two ANOVAs, and for other planned tests, are substantively identical across the two dependent variables. As a result, we report overall results for both ATTEND and FAIRPRICE but report detailed results for ATTEND only. Subjects' mean responses across the experimental conditions are summarized in Table 2 .

As anticipated, Total Price proved to be a significant covariate (ATTEND: $\mathrm{F}_{1,467}=7.91, p<.01$; FAIRPRICE: $\mathrm{F}_{1,467}=41.37, p<.001$ ), and the mean likelihood of attending the third play and the mean fair price monotonically increased as the total amount paid for tickets increased from $\$ 30$ to $\$ 60$. This result suggests that subjects were generally attending to the magnitude of their sunk costs in a manner consistent with Arkes and Blumer's (1985) findings.

After controlling for Total Price, a significant main effect for Conflict was found (ATTEND: $\mathrm{F}_{1.467}=57.83, p<.001$; FAIRPRICE: $\mathrm{F}_{1,467}=22.89, p<.001$ ). Subjects were significantly more likely to attend the third play when facing the undesirable move as opposed to the desirable party

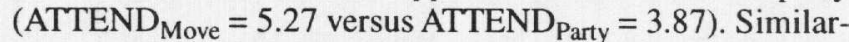
ly, their fair price was significantly higher when facing the move versus the party (FAIRPRICE $_{\text {Move }}=\$ 9.90$ versus FAIRPRICE $_{\text {Party }}=\$ 7.17$ ). Given the greater relative attractiveness of the party versus the move, this result was expected.

6For example, in the $\$ 30$ conditions, we told subjects that they had gone to the box office expecting to pay $\$ 15$ per ticket (after taxes and handling fees), for a total of $\$ 45$. We then told them that upon arriving at the box office, they were informed that the theater was running a special BTGO promotion and that the three tickets would cost a total of $\$ 30$ instead of the expected $\$ 45$. 
Table 2

MEAN LIKELIHOOD OF ATTENDING PLAY AND FAIR PRICE REQUIRED: STUDY 3

\begin{tabular}{|c|c|c|c|c|c|c|}
\hline & \multicolumn{3}{|c|}{ Conflict $=$ Party } & \multicolumn{3}{|c|}{ Conflict $=$ Move } \\
\hline & $\begin{array}{l}\text { Paid-For } \\
\text { Framing }\end{array}$ & $\begin{array}{c}\text { Ambiguous } \\
\text { Framing }\end{array}$ & $\begin{array}{c}\text { Free } \\
\text { Framing }\end{array}$ & $\begin{array}{l}\text { Paid-For } \\
\text { Framing }\end{array}$ & $\begin{array}{c}\text { Ambiguous } \\
\text { Framing }\end{array}$ & $\begin{array}{c}\text { Free } \\
\text { Framing }\end{array}$ \\
\hline \multicolumn{7}{|l|}{ Amount $=\$ 30$} \\
\hline Likelihood of attending play & 4.95 & 2.85 & 2.95 & 5.70 & 5.95 & 3.60 \\
\hline Fair price required & $\$ 7.50$ & $\$ 3.80$ & $\$ 3.75$ & $\$ 7.55$ & $\$ 8.90$ & $\$ 3.60$ \\
\hline \multicolumn{7}{|l|}{ Amount $=\$ 37.86$} \\
\hline Likelihood of attending play & 5.05 & 3.20 & 3.05 & 5.95 & 4.90 & 4.10 \\
\hline Fair price required & $\$ 8.75$ & $\$ 6.00$ & $\$ 5.35$ & $\$ 12.10$ & $\$ 8.85$ & $\$ 7.15$ \\
\hline \multicolumn{7}{|l|}{ Amount $=\$ 52.58$} \\
\hline Likelihood of attending play & 5.20 & 3.35 & 3.25 & 6.05 & 4.95 & 4.25 \\
\hline Fair price required & $\$ 10.80$ & $\$ 7.00$ & $\$ 6.55$ & $\$ 13.15$ & $\$ 10.15$ & $\$ 8.55$ \\
\hline \multicolumn{7}{|l|}{ Amount $=\$ 60$} \\
\hline Likelihood of attending play & 5.75 & 3.35 & 3.50 & 6.60 & 6.75 & 4.40 \\
\hline Fair price required & $\$ 12.25$ & $\$ 6.85$ & $\$ 7.40$ & $\$ 14.75$ & $\$ 15.75$ & $\$ 8.35$ \\
\hline
\end{tabular}

Notes: $\mathbf{n}=20$ in each condition.

Furthermore, a significant main effect for frame was found (ATTEND: $\mathrm{F}_{2,467}=41.05, p<.001$; FAIRPRICE: $\mathrm{F}_{2,467}=20.84, p<.001$ ). The mean likelihood of attending the third play and the mean fair price was highest for subjects in the Paid-For condition, second highest for subjects in the Ambiguous condition, and lowest for subjects in the Free condition.

However, this main effect of Frame was qualified by a significant Conflict $\times$ Frame interaction (ATTEND: $\mathrm{F}_{2,467}=8.26, p<.001$; FAIRPRICE: $\mathrm{F}_{2,467}=4.12, p<.02$ ). As can be seen in Figure 3, this two-way interaction appears to be driven by subjects in the Ambiguous condition. As

Figure 3

EFFECT OF CONFLICT AND FRAME ON MEAN LIKELIHOOD OF ATTENDING PLAY: STUDY 3

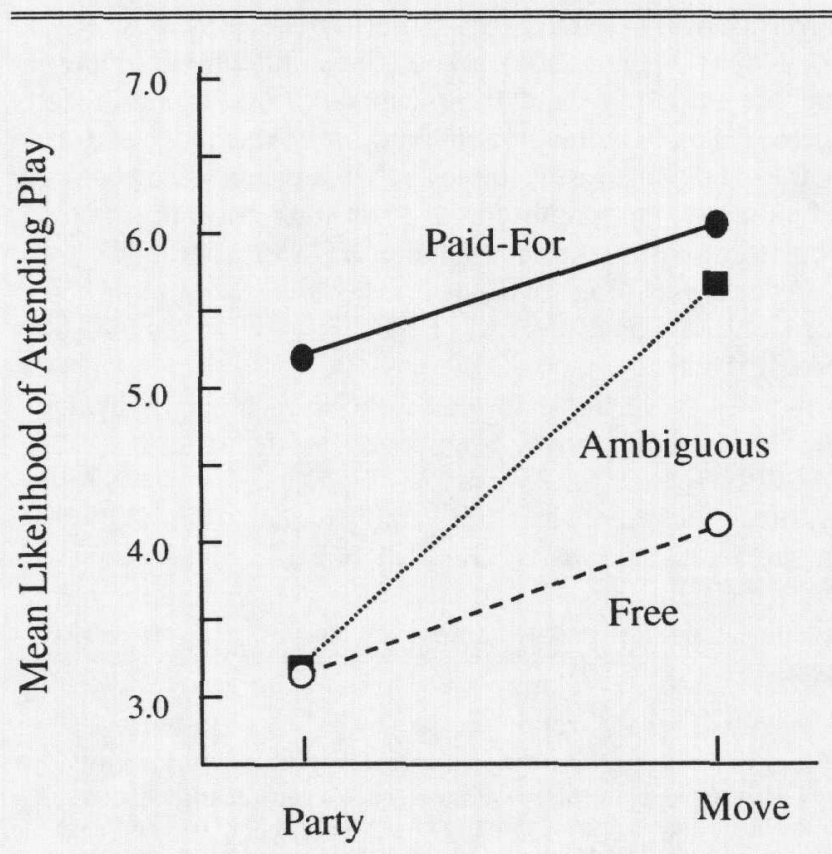

Conflict anticipated, subjects in the Paid-For condition acted as if their tickets to the third play were full priced, which resulted in a high likelihood of attendance when they faced either the party or the move. Also as anticipated, subjects in the Free condition acted as if their tickets to the third play were free, which resulted in a low likelihood of attendance when they faced either the party or the move.

In contrast, subjects in the Ambiguous condition seemed to view the cost of the third play opportunistically on the basis of the attractiveness of the conflict they faced. In direct support of the motivation hypothesis $\left(\mathrm{H}_{2}\right)$, subjects in the Ambiguous condition behaved like subjects in the Free condition when facing the party $\left(\mathrm{ATTEND}_{\text {Ambig/Party }}=\right.$ 3.19 versus ATTEND $_{\text {Free } / \text { Party }}=3.19 ; \mathrm{F}_{1,474}=.00, p=$ 1.00 ) but like subjects in the Paid-For condition when facing the move $\left(\right.$ ATTEND $_{\text {Ambig/Move }}=5.84$ versus ATTEND $\left._{\text {Paid-For/Move }}=6.08 ; \mathrm{F}_{1,474}=1.85, p>.15\right)$. The resulting $\mathrm{Z}$-shaped pattern of responses across the three Frame conditions strongly suggests that motivation can play a role in transaction decoupling.

Finally, the significant two-way Conflict $\times$ Frame interaction was qualified by a marginally significant three-way Conflict $\times$ Frame $\times$ Difficulty interaction (ATTEND: $\mathrm{F}_{2,467}=2.58, p=.077 ;$ FAIRPRICE: $\mathrm{F}_{2,467}=2.60$, $p=.075)$. As shown in Figure 4, although the Z-shaped Conflict $\times$ Frame interaction was quite pronounced for the Low Difficulty prices of $\$ 30$ and $\$ 60$, this same interaction was dampened for the High Difficulty amounts of $\$ 37.86$ and $\$ 52.58$. In particular, it appears that for High Difficulty amounts, subjects in the Ambiguous condition were likely to view their tickets as free regardless of the type of conflict they faced.

This shift toward a "free perspective" is most noticeable for subjects in the Move conditions. When difficulty was low (i.e., $\$ 30$ and $\$ 60$ ), subjects in the Ambiguous/Move condition tended to behave as if their tickets were

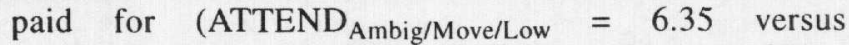
$\left.\mathrm{ATTEND}_{\text {Paid-for/Move/Low }}=6.15 ; \mathrm{F}_{1,468}=.20, p>.65\right)$ as opposed to free (ATTEND Ambig/Move/Low $=6.35$ versus $\left.\mathrm{ATTEND}_{\text {Free/Move/Low }}=4.00 ; \mathrm{F}_{1,468}=26.92, p<.001\right)$. In contrast, when difficulty was high (i.e., $\$ 37.86$ and $\$ 52.58$ ), subjects in the Ambiguous/Move condition tended to behave more as if their tickets were free $\left(\mathrm{ATTEND}_{\mathrm{Ambig} / \mathrm{Move} / \mathrm{High}}=4.93\right.$ 
Figure 4

EFFECT OF CONFLICT, FRAME, AND AMOUNT ON MEAN LIKELIHOOD OF ATTENDING PLAY: STUDY 3
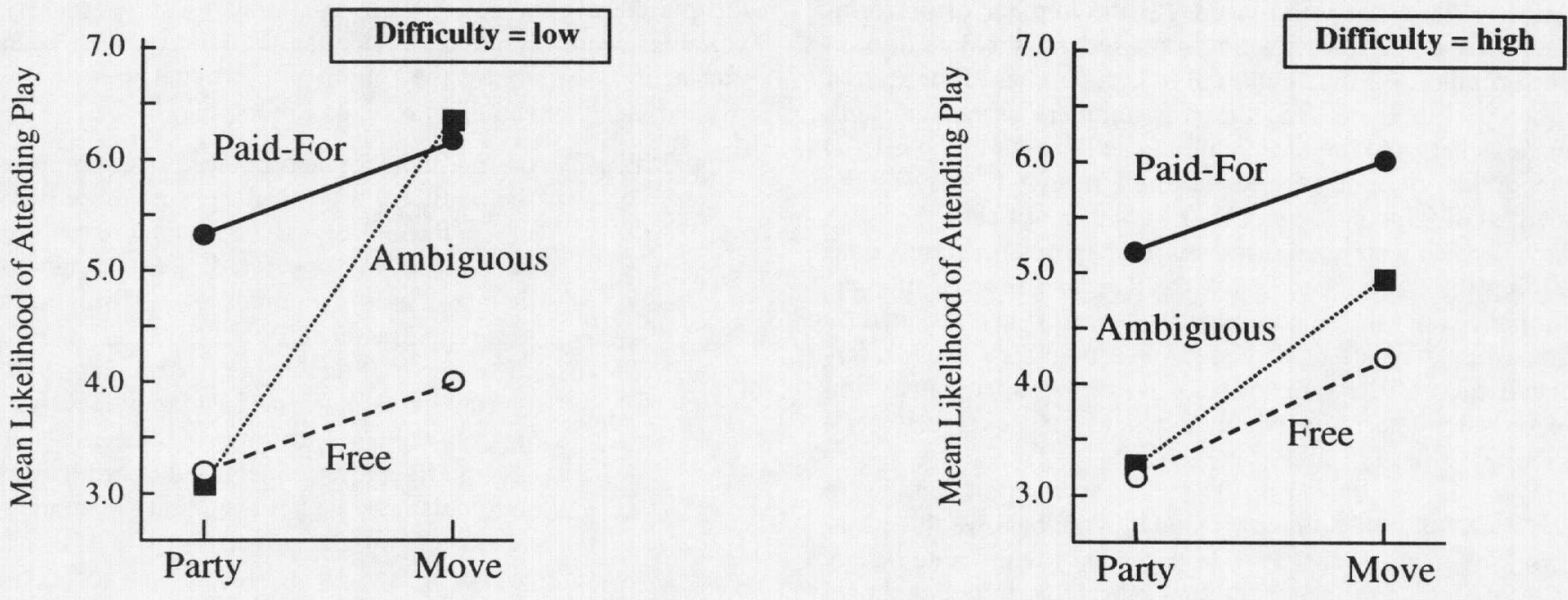

versus ATTEND $\mathrm{Free}_{\mathrm{Party} / \mathrm{High}}=4.18 ; \mathrm{F}_{1,468}=2.74, p=.098$ ) than paid for $\left(\mathrm{ATTEND}_{\mathrm{Ambig} / \mathrm{Move} / \mathrm{High}}=4.93\right.$ versus $\mathrm{ATTEND}_{\text {Free/Move/High }}=6.00 ; \mathrm{F}_{1,468}=5.63, p<.02$ ). This noticeable trend toward viewing ambiguously priced tickets as free under High Difficulty conditions, regardless of the valence of the conflict, provides support for the difficulty hypothesis $\left(\mathrm{H}_{3}\right)$.

Thus, it appears that as the total cost of the tickets became increasingly difficult to allocate across the three plays, subjects tended to decouple the costs and benefits of the third play, which decreased their likelihood of attending the play. In this regard, this third study provides some limited evidence that allocation difficulty also contributes to transaction decoupling.

\section{Discussion}

This third study tested two explanations for transaction decoupling. If decoupling is motivationally driven, we would expect attendance to vary on the basis of the desirability of the conflict faced by subjects. We found compelling evidence that this was the case: When ticket pricing was ambiguous, subjects seemed to allocate costs to the third play opportunistically. Specifically, subjects behaved as if the third play was free when faced with the desirable party, leading to a low likelihood of attending the play, but they behaved as if the third play was full priced when faced with the undesirable move, leading to a high likelihood of attending the play.

This suggests that transaction decoupling can be motivationally driven. In particular, when faced with an unattractive benefit (e.g., skiing in poor conditions) or an attractive alternative benefit (e.g., a party), consumers appear to decouple costs from benefits opportunistically so as to experience minimal sunk cost pressure. Similarly, when faced with an attractive benefit (e.g., skiing in ideal conditions) or an unattractive alternative benefit (e.g., helping a friend move), consumers appear to couple costs and benefits so as to experience maximum sunk cost pressure.

We also found evidence (albeit marginal) to suggest that transaction decoupling can be cognitively driven. In partic- ular, as the allocation of costs across the three theater tickets became increasingly difficult, we found that subjects in the ambiguous framing condition increasingly behaved as if the tickets to the third play were free. Such a result suggests that when costs become cognitively difficult to allocate across benefits, subjects forgo allocating those costs, thereby decreasing sunk cost pressure to consume the benefit.

In summary, Study 3 provides strong evidence that transaction decoupling has a motivational cause. It also provides some limited evidence that decoupling has a cognitive cause.

\section{STUDY 4}

Studies 1, 2, and 3 were pencil-and-paper tasks designed to test for and explore transaction decoupling through the use of hypothetical scenarios. Study 4 was undertaken to provide external validity for the phenomenon. Using actual transaction and attendance data from a summer theater series, Study. 4 employed two logistic regressions to test whether ticket bundling (i.e., purchasing tickets to multiple plays) adversely affected a person's theater attendance, after other potential contributory factors (e.g., ticket price, method of payment) were controlled for.

\section{Description of the Data}

Study 4 was a field study that used historic transaction and attendance data from a 1997 Summer Shakespeare Festival (SSF). The festival presented four Shakespearean plays in rotation from June to August, resulting in 64 separate performances. In total, the SSF staff provided raw data on approximately 1250 transactions, accounting for almost 9700 individual tickets. After some screening, described subsequently, we retained data on 923 transactions that accounted for 6070 individual tickets. ${ }^{7}$ Mean likelihood of attendance across these 6070 tickets was $84.5 \%$.

\footnotetext{
${ }^{7}$ Results of analyses run on the prescreened data do not differ substantively from results of analyses run on the screened data.
} 
The raw data. Theatergoers typically advance purchased tickets to SSF performances by mail, by telephone, or in person, resulting in a paper transaction record in each case. The information contained in a transaction record included (1) the date the order was placed, (2) the number of performances for which tickets were purchased, (3) the date of each performance, (4) the number of tickets purchased for each of those performances, (5) the seat numbers associated with those tickets, (6) the face value of each ticket purchased, (7) the dollar amount of any discount received, and (8) the method of payment (e.g., check versus credit card). ${ }^{8}$

When a theatergoer used his or her ticket, a stub containing the name of the play, the date and time of the performance, and the seat number was torn off and retained by the usher. As part of this study, we manually cross-referenced each of these ticket stubs with the paper transaction records to determine whether a paid-for ticket had been used.

Screening of the data. The raw transaction data were screened for inclusion in this study on the basis of three factors. The first two factors were intended to eliminate tickets that might be part of institutional sales (e.g., bulk ticket purchases by corporations). Given that holders of such tickets might have received those tickets for free from their employers, we believed that the inclusion of such tickets could bias results in favor of decoupling. Therefore, to allow for a more conservative test of decoupling, we eliminated (1) transactions in which more than six tickets were purchased for any given performance and (2) transactions in which tickets to different showings of the same play were purchased. Although these criteria were not perfectly diagnostic, we believed that they were far more representative of institutional purchases than of personal purchases.

To facilitate data analysis, we also eliminated transactions in which the degree of bundling was vague. For example, one person purchased two $\$ 10$ tickets to the first of four plays and four $\$ 24$ tickets to each of the remaining three plays. As such, we questioned whether to treat the $\$ 10$ tickets as unbundled tickets to a single play or as bundled tickets to one of four plays. To simplify matters, we eliminated transactions in which a person had purchased either varying numbers of tickets across performances or tickets of varying prices across performances. On the basis of these three screening criteria, we retained data for 6070 tickets.

\section{The Logistic Regressions}

We employed two logistic regressions to estimate a person's likelihood of using a given ticket as a function of the transaction characteristics surrounding the purchase of that ticket. In these regressions, our dependent measure was ticket usage, which was coded as 0 for nonusage and 1 for usage.

\footnotetext{
8For example, a transaction record might show that on May 15, a customer purchased four tickets each to Romeo and Juliet on July 18 (seat numbers C 15-C18) and Much Ado About Nothing on August 1 (seat numbers D11-D14). In addition, this record might show that the face value of each ticket was $\$ 22$ but that the customer obtained a $\$ 2$ per ticket discount for being a senior citizen. Finally, the record might show that the customer paid by credit card.
}

We included five explanatory variables, each of which was derived from the paper transaction records. ${ }^{9}$ The first of these, NUMPERF, was the explanatory variable of interest and captured the degree of product bundling associated with the purchase of a ticket. The remaining four explanatory variables were included to account for factors other than transaction decoupling that might affect ticket usage. The five explanatory variables were as follows:

NUMPERF $=$ the number of performances purchased by the holder of a given ticket (taking on values 1 through 4). Because of transaction decoupling, we expected ticket usage to decrease as the number of performances purchased increased.

NUMTKTS $=$ the number of tickets per performance purchased by the holder of a given ticket (taking on values 1 through 6 ). Because of group effects (e.g., increased coordination and logistics), we believed that the number of tickets might adversely affect ticket usage.

DAYSB4 = the number of days before the performance a ticket had been purchased (taking on values 0 through $150+$ ). Because of payment depreciation (Gourville and Soman 1998), we expected attendance to decrease as DAYSB4 increased.

TKTPRICE $=$ the actual price paid for a given ticket (taking on values of $\$ 10$ to $\$ 36$ and equal to a ticket's face value less any discount received). Because of the sunk cost effect (Arkes and Blumer 1985), we expected ticket usage to increase as TKTPRICE increased.

PAYFORM = the form of the payment (taking on values of 0 for check/cash and 1 for credit card). Although Prelec and Loewenstein (1998) suggest that credit card usage promotes transaction decoupling, such decoupling would be confounded with an expected wealth effect associated with credit card usage. In either case, we expected ticket usage to decrease with credit card usage.

\section{Results}

Initial analysis. Employing all 6070 tickets in the screened data set, an initial logistic regression provided support for transaction decoupling. First, the overall model proved significant $\left(\chi^{2}(5)=3184.42, p<.001\right)$. Second, three of our four secondary explanatory variables were significant and affected usage as expected, as shown in Table 3.

Finally, our explanatory variable of interest, NUMPERF, proved significant $\left(\chi^{2}(1)=22.23, p<.001\right)$ and affected ticket usage as predicted. As shown in the bottom rows of Table 4, across all plays purchased, the likelihood of using a ticket was greatest if that ticket was part of a single-play

\footnotetext{
${ }^{9}$ There is no reason to believe that multicollinearity is a concern among these five explanatory variables. First, none of these variables affected attendance in an unexpected direction (i.e., no sign reversals). Second, intercorrelations among these five variables were modest to slight (i.e., one pairwise correlation was .47 ; all others were below .20 ).
} 
Table 3

LOGISTIC REGRESSION RESULTS: STUDY 4

\begin{tabular}{|c|c|c|c|c|c|c|}
\hline \multirow[b]{2}{*}{$\begin{array}{l}\text { Explanatory } \\
\text { Variable }\end{array}$} & \multicolumn{3}{|c|}{ First-Cut Regression $(n=6070)$} & \multicolumn{3}{|c|}{ First-Play-Only Regression $(n=2565)$} \\
\hline & $\begin{array}{c}\text { Parameter } \\
\text { Estimate }\end{array}$ & $\begin{array}{c}\text { Chi-Square } \\
\text { Value }\end{array}$ & $p$-Value & $\begin{array}{c}\text { Parameter } \\
\text { Estimate }\end{array}$ & $\begin{array}{c}\text { Chi-Square } \\
\text { Value }\end{array}$ & p-Value \\
\hline NUMPERF & .4625 & 22.23 & .0001 & .5965 & 19.87 & .0001 \\
\hline NUMTKTS & .0281 & .35 & .5563 & -.1220 & 1.57 & .2106 \\
\hline DAYSB4 & .0693 & 605.96 & .0001 & .0557 & 13.98 & .0001 \\
\hline TKTPRICE & -.5552 & 763.32 & .0001 & -.4087 & 167.48 & .0001 \\
\hline PAYFORM & 3.6451 & 462.57 & .0001 & 3.3685 & 105.28 & .0001 \\
\hline INTERCEPT & -5.3824 & 166.97 & .0001 & -5.8433 & 77.94 & .0001 \\
\hline Overall Model & & 3184.42 & .0001 & & 742.32 & .0001 \\
\hline
\end{tabular}

Notes: The degrees of freedom for the Wald chi-square tests are 1 for the explanatory variables and 5 for the overall model.

Table 4

LIKELIHOOD OF TICKET USAGE AS A FUNCTION OF NUMBER OF PERFORMANCES PURCHASED AND SEQUENCE OF PERFORMANCES: STUDY 4

\begin{tabular}{|c|c|c|c|c|c|}
\hline \multirow[b]{2}{*}{ Play Sequence for Each Ticket Holder } & \multicolumn{4}{|c|}{ Number of Plays Purchased by Ticket Holder } & \multirow{2}{*}{$\begin{array}{c}\text { Across All } \\
\text { Ticket Holders }\end{array}$} \\
\hline & One Play & Two Plays & Three Plays & Four Plays & \\
\hline \multicolumn{6}{|l|}{ First Play } \\
\hline Total tickets purchased & $1191^{\mathrm{a}}$ & $283^{\mathrm{b}}$ & 51 & 1040 & 2565 \\
\hline Number of no-shows & 7 & 8 & 4 & 164 & 183 \\
\hline Attendance rate & .994 & .972 & .922 & .842 & .929 \\
\hline \multicolumn{6}{|l|}{ Second Play } \\
\hline Total tickets purchased & & 283 & 51 & 1040 & 1374 \\
\hline Number of no-shows & & 12 & 9 & 205 & 226 \\
\hline Attendance rate & & .958 & .824 & .803 & .836 \\
\hline \multicolumn{6}{|l|}{ Third Play } \\
\hline Total tickets purchased & & & 51 & 1040 & 1091 \\
\hline Number of no-shows & & & 7 & 238 & 245 \\
\hline Attendance rate & & & .843 & .771 & .794 \\
\hline \multicolumn{6}{|l|}{ Fourth Play } \\
\hline Total tickets purchased & & & & 1040 & 1040 \\
\hline Number of no-shows & & & & 288 & 288 \\
\hline Attendance rate & & & & .723 & .723 \\
\hline \multicolumn{6}{|l|}{ Across All Plays } \\
\hline Total tickets purchased & 1191 & 566 & 153 & 4160 & 6070 \\
\hline Number of no-shows & 7 & 20 & 20 & 895 & 942 \\
\hline Attendance rate & .994 & .965 & .869 & .785 & .845 \\
\hline
\end{tabular}

aTo be read, "1191 tickets were purchased by people who bought tickets to one play only. Of these, 7 tickets went unused, for an attendance rate of .994."

bTo be read, " 283 tickets to each of two plays were purchased by people who bought tickets to exactly two plays. Of those, 8 tickets went unused for the first play purchased, and 12 tickets went unused for the second play purchased."

purchase $(\mathrm{P}[$ usagelone-play $]=99.4 \%)$ but declined steadily if it was part of a two-play purchase (P[usageltwoplays $]=96.5 \%$ ), a three-play purchase (P[usagelthreeplays $]=86.9 \%)$, or a four-play purchase ( $\mathrm{P}$ [usagelfourplays $]=78.5 \%$ ).

First-play-only analysis. Although the first regression controlled for several important factors, it did not control for satiation (e.g., "I have no desire to see another play") or for learning (e.g., "I expected the staging to be more professional") that might have adversely affected attendance for multiple-play ticket holders but not for single-play ticket holders.

To control for these factors and to provide a more conservative test of decoupling, we ran a second logistic regression in which we only considered ticket usage to the first play for which a ticket was purchased by each individual. This resulted in the inclusion of all the tickets purchased by oneplay ticket holders, for whom "one play" and "first play" were synonymous. It also resulted in the inclusion of tickets to the first play for which a ticket was purchased by all twoplay, three-play, and four-play ticket holders. More important, however, it also resulted in the exclusion of tickets to all subsequent plays for these multiple-play ticket holders, thereby eliminating any tickets that might have been influenced by satiation or learning. Because of this modification to the data, we retained data for 2565 individual tickets. Mean likelihood of attendance across these 2565 tickets was $92.8 \%$.

The results of this first-play-only analysis also supported our predictions. Again, the overall model was significant $\left(\chi^{2}(5)=742.32, p<.001\right)$; three of the secondary explanatory variables were significant and affected usage as expected. More important, NUMPERF was also significant $\left(\chi^{2}(1)=19.87, p<.001\right)$ and affected usage as predicted. As shown in the top rows of Table 4 , as the number of plays purchased by a person increased from one to four plays, 
first-play ticket usage decreased from a high of $99 \%$ (i.e., $\mathrm{P}$ [first play ticket usagelone-play] $=99.4 \%$ ) to a low of $84 \%$ (i.e., P[first play ticket usagelfour-plays] $=84.2 \%$ ).

\section{Discussion}

Using transaction and attendance data from a 1997 SSF, we found that a person's likelihood of using a paid-for theater ticket was a direct function of the number of plays that the person had purchased, all else held constant. Theatergoers who had purchased tickets to a single play were almost certain to use those tickets. This is consistent with our argument that in a one-to-one transaction (i.e., one payment, one benefit), the costs and benefits of that transaction are tightly coupled, resulting in strong sunk cost pressure to consume the pending benefit. However, theatergoers who had purchased tickets to four plays were only $84 \%$ likely to use their first-play tickets and only $78 \%$ likely to use any given ticket across the four plays. Again, this is consistent with our argument that in a one-to-many transaction (i.e., one payment, many benefits), the costs and benefits of the transaction become decoupled, resulting in only weak sunk cost pressure to consume the pending benefits.

\section{GENERAL DISCUSSION}

\section{Summary of Research}

Across four studies, we have shown that consumers are more likely to forgo consumption and demand less compensation for an individual benefit that is purchased as part of a bundle. We attribute these effects to transaction decoupling - the disassociation of a product's costs and benefits as a result of price bundling. Study 1 established the existence of transaction decoupling. Study 2 helped isolate the effects of decoupling from those of the psychophysics of aggregated costs (Thaler 1985). Study 3 identified consumer motivation and cost allocation difficulty as two causes for decoupling. Finally, Study 4 provided external validity for decoupling by demonstrating its impact in a real-world consumer setting. Together, these studies provide strong evidence that transaction decoupling is real and that it significantly affects product consumption.

\section{Theoretical Implications}

When it comes to consumption behavior, it has long been known that people sometimes deviate from normative economic principles. One such deviation is the well-known sunk cost effect. Although many potential explanations for the sunk cost effect exist (see Arkes and Blumer 1985; Brockner 1992; Staw 1976; Teger 1980; Thaler 1980, 1985), each shares the common characteristic that a person must account for the (sunk) cost of a transaction and factor that cost into the subsequent consumption decision.

Recent research suggests that this accounting for (sunk) costs may be influenced by the physical characteristics of a transaction, such as the relative timing of payment and consumption (Gourville and Soman 1998) and the payment mechanism used to complete the transaction (Prelec and Loewenstein 1998). In the present research, we focus on the common marketing practice of price bundling and show that price bundling leads to a decoupling of the sunk costs and pending benefits of a given transaction, thereby reducing the likelihood of downstream consumption. Furthermore, we identify consumer motivation as one cause of this decou- pling, introducing the interesting possibility that the accounting for and consideration of sunk costs can be selective and self-serving. We hope to explore this finding in further research.

\section{Managerial Implications}

In addition to providing theoretical insights into consumption behavior, the current research has some important managerial implications.

The management of consumption. One important implication of transaction decoupling involves the management of product consumption. We have shown that the common marketing practice of price bundling can lead to a systematic decrease in actual (as opposed to paid) demand for an offered service. In anticipation of this relationship between bundling and service demand, a marketer could (1) proactively discourage or encourage service consumption or (2) passively anticipate actual service demand to manage scarce resources better.

As an example of proactively discouraging service consumption, consider a ticket manager who has responsibility for maximizing revenues across a series of fixed-capacity sporting events. Transaction decoupling would suggest that this ticket manager could price-bundle the events (e.g., offer season tickets), with the knowledge that this price bundling would decrease actual attendance for the individual events within the bundle. In turn, this would enable the ticket manager to oversell each event and increase revenues.

Alternatively, the provider of a virtuous service could psychologically unbundle its offerings so as to encourage consumption. Consider a health care clinic that wishes to promote routine physical exams among its patients. After recruiting patients with a single bundled fee, this provider could itemize or highlight the cost of each procedure covered within the bundled fee. ${ }^{10}$ In doing so, the clinic would facilitate a one-to-one coupling of the costs and benefits of the annual exam, thereby increasing a patient's likelihood of undergoing such an exam (e.g., "I've paid for it, I'd better take advantage of it").

In a more passive and less manipulative fashion, a service provider could anticipate actual demand given the naturally occurring mix of bundled and unbundled transactions. For example, theater managers might expect a no-show rate of $20 \%$ when the percentage of season ticket holders is high but a no-show rate of only $5 \%$ when the percentage of season ticket holders is low. With this knowledge, theater managers could manage their expenses and/or revenues more efficiently. First, they could better allocate resources on the basis of anticipated demand (e.g., scheduling fewer ushers when no-show rates are expected to be high). Second, they could maximize attendance by practicing a form of "yield management." In much the same way that an airline oversells a flight in anticipation of a predictable percentage of no-shows, theater managers could oversell performances for which the no-show rate is expected to be high but not oversell performances for which the no-show rate is expected to be low.

16) We have assumed that a person's likelihood of purchasing medical cov erage will be unaffected by this itemization. If it is affected, we would need to include the first-stage effect of itemization on purchase likelihood to arrive at a two-stage or net effect of itemization on consumption. 
Volume purchasing. A second important implication of transaction decoupling involves its potential role in accelerating the consumption of physical goods purchased in bulk (e.g., cases of wine, multipacks of snacks). To this point, we have considered the effect of price bundling on the consumption of a service that is due to expire, such as a datestamped theater ticket. The pending benefit of a physical good typically remains until the good is consumed, however. As with services, the price bundling of physical goods should result in decoupling that reduces a consumer's attention to the (sunk) costs of the pending benefit. In contrast to services, however, this should increase the likelihood of consuming the physical good by reducing the benefit required for consumption to take place (Gourville and Soman 1998).

Consider the purchase of an expensive bottle of wine, which can be inventoried until needed. When the wine is purchased as a single unit, its cost and eventual benefit are tightly coupled. As a result, the cost of the wine will be quite salient, and a person will likely reserve that wine for a special occasion. When purchased as part of a bundle (e.g., as part of a case of wine), however, the cost and benefit of that individual bottle of wine will likely become decoupled, reducing the impact of cost on eventual consumption. ${ }^{11}$ As a result, a person will likely find the wine appropriate for many more (not-so-special) occasions.

Thus, in contrast to the price bundling of services, the price bundling of physical goods could lead to an increase in product consumption. If this is the case, transaction decoupling would present an additional explanation for the general finding that purchasing a product in volume can lead to its accelerated consumption (e.g., Ailawadi and Neslin 1998; Wansink 1996).

\section{Directions for Further Research}

Although the present research establishes a main effect between price bundling and transaction decoupling, several avenues for future research would further our understanding of the phenomenon. First, by manipulating the relative attractiveness of the target benefit, we have demonstrated that decoupling is moderated by a person's motivation to link costs to benefits. However, other factors that drive motivation would be worth exploring. In particular, a person's motivation to couple costs and benefits could be a function of involvement with a product category and/or the total price paid for the product. For example, would an avid theatergoer be as quick to decouple the costs and benefits of a given play as a novice theatergoer? Similarly, would a skier be as likely to decouple the costs and benefits of a day of skiing if that day had cost $\$ 100$ as opposed to $\$ 40$ ?

Second, we also have demonstrated that decoupling is moderated by the cognitive difficulty a consumer experiences in allocating costs across benefits. We did this by

IFor simplicity, this illustration ignores the effects of payment depreciation (Gourville and Soman 1998) and the psychophysics of bundled costs (Thaler 1985). In addition to transaction decoupling, these two effects should contribute to the increased likelihood of consuming a wine purchased in bulk and intended for cellaring. manipulating price so that it was either easy to allocate (e.g., $\$ 30$ ) or difficult to allocate (e.g., \$37.86) across three plays. There are many other ways that price bundling could affect ease of allocation, however. For example, the prices of individual items within a bundle could vary. When buying a case of wine, consumers could mix and match wines of different prices, making it extremely difficult to mentally account for the cost of any one bottle. When it comes time for consumption, how do consumers account for the cost of an item purchased in such a manner? Are they sensitive to the differences in price paid across the bottles of wine? Or do they consider the average price paid for each of the 12 bottles? Or perhaps they ignore price altogether?

Finally, in our investigation of transaction decoupling, we have focused on transactions in which a single payment resulted in multiple benefits. However, decoupling is also likely to occur when many payments result in a single benefit, as in the case of a layaway transaction. And decoupling will almost certainly occur when multiple payments result in multiple benefits, as in the case of multipart pricing transactions. Future empirical work should include these other categories of exchange for the purpose of developing a more comprehensive theoretical understanding of transaction decoupling.

\section{REFERENCES}

Ailawadi, Kusum L. and Scott A. Neslin (1998), "The Effect of Promotion on Consumption: Buying More and Consuming It Faster," Journal of Marketing Research, 35 (August), 390-98.

Arkes, Hal R. (1996), "The Psychology of Waste," Journal of Behavioral Decision Making, 9 (3), 213-24.

- and Catherine Blumer (1985), "The Psychology of Sunk Cost," Organizational Behavior and Human Decision Processes, 35 (February), 124-40.

Brockner, Joel (1992), "The Escalation of Commitment to a Failing Course of Action: Toward Theoretical Progress," Academy of Management Review, 17 (1), 39-61.

Dolan, Robert J. and Hermann Simon (1996), Power Pricing. New York: The Free Press.

Drumwright, Minette E. (1992), "A Demonstration of Anomalies in Evaluations of Bundling," Marketing Letters, 3 (4), 311-21.

Estelami, Hooman (1999), "The Computational Effect of Price Endings in Multi-dimensional Price Advertising," Journal of Product and Brand Management, 8 (3), 244-56.

Gaeth, Gary J., Irwin P. Levin, Goutam Chakrabarty, and Aron M. Levin (1990), "Consumer Evaluations of Multi-product Bundles: An Information Integration Analysis," Marketing Letters, 2 (January), 47-57.

Garland, Howard and Stephanie Newport (1991), "Effects of Absolute and Relative Sunk Costs on the Decision to Persist with a Course of Action," Organizational Behavior and Human Decision Processes, 48 (February), 55-69.

Gourville, John T. and Dilip Soman (1995), "Transaction Decoupling: When Costs and Benefits Become Losses and Gains," poster presented at the Annual Meeting for the Society for Judgment and Decision Making, Los Angeles (November 11-13). and (1998), "Payment Depreciation: The Behavioral Effects of Temporally Separating Payments from Consumption," Journal of Consumer Research, 25 (September), 160-74.

Guiltinan, Joseph P. (1987), “The Price Bundling of Services," Journal of Marketing, 51 (April), 74-85.

Hanson, Ward and R. Kipp Martin (1990), "Optimal Bundle Pricing," Management Science, 36 (2), 155-74.

Harlam, Bari A., Aradhna Krishna, Donald R. Lehmann, and Carl Mela (1995), "Impact of Bundle Type, Price Framing and 
Familiarity on Purchase Intention for the Bundle," Journal of Business Research, 33 (1), 57-66.

Kahneman, Daniel and Amos Tversky (1979), "Prospect Theory: An Analysis of Decision Under Risk," Econometrica, 47 (2), 363-91.

Prelec, Drazen and George Loewenstein (1998), "The Red and the Black: Mental Accounting of Savings and Debt," Marketing Science, 17 (1), 4-28.

Simonson, Itamar and Barry M. Staw (1992), "Deescalation Strategies: A Comparison of Techniques for Reducing Commitment to Losing Courses of Action," Journal of Applied Psychology, 77 (4), 419-26.

Staw, Barry M. (1976), "Knee-Deep in the Big Muddy: A Study of Escalating Commitment in a Chosen Course of Action," Organizational Behavior and Human Performance, 16 (June), $16-44$
Teger, A.I. (1980), Too Much Invested to Quit: The Psychology of the Escalation of Conflict. New York: Pergamon Press.

Thaler, Richard H. (1980), "Toward a Positive Theory of Consumer Choice," Journal of Economic Behavior and Organization, 1, $39-60$.

(1985), "Mental Accounting and Consumer Choice," Marketing Science, 4 (3), 199-214.

Wansink, Brian (1996), "Can Package Size Accelerate Usage Volume?" Journal of Marketing, 60 (3), 1-14

Whyte, Glen (1986), "Escalating Commitment to a Course of Action: A Reinterpretation," Academy of Management Review, 11 (April), 311-21

Yadav, Manjit S. and Kent B. Monroe (1993), "How Buyers Perceive Savings in a Bundle Price: An Examination of a Bundle's Transaction Value," Journal of Marketing Research. 30 (August), 350-58.

\section{Strategic Insig}

Dick Westwood and the Strategy \& Tactics team of professionals provide the insights your marketing needs:

- How your market actually works

- What your brand's equities really are

- How to build a path to more growth

Whether it's a segmentation study, a brand image sto a brand extendibility study - or any other area of stra research - we provide the extra level of marketing insight that makes the work pay off for you.

Call us for an initial consultation. Bring your issues and objectives. We'll design a research program to bring your marketing to the next level. 